\title{
Inflación y crisis nacional. Culturas económicas y espacios públicos en la Argentina y Brasil
}

\author{
Federico Neiburgl \\ Universidade Federal de Rio de Janeiro
}

Este artículo describe algunos aspectos de la construcción de la asociación entre inflación y crisis nacional en Brasil y la Argentina, explorando la relación entre dos procesos: la progresiva transformación de los profesionales de la economía en intelectuales públicos, y el paso de formas cualitativas de percepción del desequilibrio monetario a formas eminentemente cuantitativas de representar la inflación. Ambos procesos son paralelos a la transformación de los saberes económicos en verdaderas culturas económicas, en un idioma que ha servido para describir los problemas nacionales más allá del estrecho mundo de los especialistas. El horizonte temporal del artículo se inicia hacia mediados del siglo XX, cuando se reconfigura el campo de los profesionales de la economía en ambos países, y termina hacia mediados de la década de 1980 cuando se lanza una serie de planes de estabilización monetaria conocidos como "heterodoxos".

PALABRAS ClAVE: inflación, crisis, culturas económicas, espacios públicos, el Brasil, la Argentina.

This article describes some aspects of the association between inflation and national crisis in Brazil and Argentina, exploring the relationship between two processes: the transformation of the professionals of economics in public intellectuals, and the shift from qualitative to quantitative perceptions of monetary instability, parallel to the transformation of index numbers in "social numbers", which deserve public trust. Both processes coincide with the transformation of the economic knowledge in economic cultures, an idiom which serves to describe national problems outside the close world of specialists. The article describes a period which begins in the middle of the XX Century, when the field of economist on these countries was reconfigured, and the middle of the 1980s, when the stabilizations plans known as "heterodox" were lunched.

KEYwoRDs: inflation, crisis, economic cultures, public spheres, Brazil, Argentina.

1 Programa de Pós-Graduação em Antropologia Social, Núcleo de Pesquisas em Cultura e Economia, Museu Nacional, Universidade Federal de Rio de Janeiro, Brasil. Este artículo es resultado de una investigación en curso que tiene por objetivo la historia cultural comparada de la inflación en Brasil y la Argentina. Parte del material aquí presentado ha sido utilizado en otras publicaciones preliminares, especialmente en Neiburg, F.: "Economistas e culturas econômicas no Brasil e na Argentina: notas para uma comparação a propósito das heterodoxias", Tempo Social. Revista de sociología da USP, 16 (2), 2004, págs. 177-203. 
En los primeros meses del año 2002 la BBC de Londres publicó en su página de Internet un Dictionary of Argentine Crisis con la finalidad de ayudar a sus lectores a comprender la geografía de asuntos invocados por términos como "convertibilidad", "bonos", "pesificación", "dolarización" o "corralito". Mientras los no familiarizados con los acontecimientos que conmovían al país en ese momento podían informarse por ese y otros medios sobre lo que allí estaba aconteciendo, los argentinos debatían la crisis en las calles, al tiempo que los intelectuales de mayor renombre del país poblaban páginas de diarios y revistas discutiendo los destinos de la nación; algunos incluso se preguntaban sobre la posibilidad de que éste simplemente dejara de existir.

En el vecino Brasil, el fantasma de la "argentinización" se agitaba en todo debate público sobre los destinos de la economía y la política. Y no era la primera vez que eran invocados los riesgos de la contigüidad, siempre tan afines con la dimensión internacional del desequilibrio financiero. Desde hacía unos veinte años varias habían sido las expresiones (como la teoría del "efecto Orloff", según el cual, se decía, "la Argentina de hoy es el Brasil de mañana") que describían la pérdida súbita de valor de las monedas nacionales en términos de contagio. ${ }^{2}$

De hecho, el desequilibrio monetario no era novedad para argentinos y brasileros. Desde hacía tiempo que las poblaciones de ambos países convivían con fenómenos semejantes, aprendiendo a identificar la pérdida del valor de sus monedas con representaciones respecto de las crisis nacionales. El propósito de este trabajo es describir algunos aspectos de la construcción de semejante asociación entre inflación y crisis nacional en Brasil y la Argentina, explorando la relación entre dos procesos:

1) La progresiva transformación de los profesionales de la economía (académicos, funcionarios de agencias internacionales y de gobiernos, periodistas, operadores de mercado, etc.) en intelectuales públicos; paralela a la consagración del fenómeno inflacionario en un problema nacional de primera magnitud y a la modernización del campo de los especialistas

2 Está por hacerse aun un estudio de la asociación, en las teorías nativas y el sentido común (también erudito), entre el uso excesivo de bebidas alcohólicas (como los supuestos en las ideas de efecto tequila, caipirinha, y tantos otros, aparte del Orloff) y otras enfermedades, y la difusión de las crisis monetarias. Para una propuesta general en este sentido, a propósito del "efecto Orloff", ver Neiburg, F.: "Economistas y elites estatales en el Brasil y la Argentina, 1980-2000. Esbozo de una sociología comparada de la cultura a propósito del "efecto Orloff", Prismas. Revista de historia intelectual, Vol. 8, 2004, pág. 215. 
(que ocurre en la segunda mitad del siglo XX, con la americanización de la economía académica y la construcción de un nuevo perfil profesional);

2) El paso de formas eminentemente cualitativas de percepción del desequilibrio monetario a formas eminentemente cuantitativas de representar la inflación, ligadas a la proliferación de los index numbers, que ocurre como un efecto de la ampliación del campo de los especialistas (reclutados para producir indicadores de variación de precios por los nuevos organismos estatales, empresariales y de investigación académica) y, paralelamente, a la transformación de esos indicadores en "números sociales", objeto de confianza pública (sancionando el doble papel de todo indicador: describir variaciones pasadas y organizar mercados futuros).

De hecho, y eso también interesa de modo central a este texto, si bien la asociación entre inflación y crisis nacional es un rasgo común de la historia reciente de Brasil y la Argentina, los contenidos específicos atribuidos a dichos términos en cada caso varían. Describir, aunque más no sea de forma exploratoria, esos contenidos diferenciales es un objetivo adicional de este texto. Del lado argentino encontramos la actualización de un relato que gira en torno a dos motivos: la excepción y la decadencia; del lado brasilero, una narrativa que habla de desvíos respecto de un destino de grandeza. La participación de los profesionales de la economía en la elaboración de fórmulas distintas para estos viejos motivos confiere nuevas modulaciones a la narrativa sobre la crisis, legitimando a aquellos que la formulan como figuras públicas, capaces de develar los más profundos dilemas nacionales a través del uso científico de los instrumentos de la más auténtica ciencia social, la ciencia de los números: la moderna economía académica.

El relato que se presenta a continuación se inicia hacia mediados de la década de 1980, en el punto culminante de este proceso: el lanzamiento, un poco antes en la Argentina que en Brasil, de la primera generación de los planes de estabilización monetaria conocidos como "heterodoxos". A partir de allí, el texto retrocede unos 30 años para mostrar algunos aspectos del lento proceso de transformación de los profesionales de la economía en intelectuales públicos y el también lento proceso de cultivación económica de las poblaciones de ambos países; paralelos ambos a la transformación de los saberes económicos en verdaderas culturas económicas, en un idioma que ha servido para describir los problemas nacionales más allá del estrecho mundo de los especialistas. 


\section{Inflación y crisis nacional}

El lunes 22 de abril de 1985 los diarios de Buenos Aires informaron en grandes titulares el inicio del juicio a las Juntas Militares que habían gobernado el país entre marzo de 1976 y diciembre de 1983. Con una singular intensidad los argentinos eran expuestos al pasado reciente de autoritarismo y violencia. Ese mismo día, el presidente Raúl Alfonsín denunció públicamente que la naciente democracia estaba amenazada y llamó a los ciudadanos para que el viernes acudieran a la Plaza de Mayo, principal centro político y simbólico del país. Más de 200.000 personas respondieron a su llamado. El presidente comenzó sus palabras mencionando la "grave crisis" por la que atravesaba la nación, pero dio un giro inesperado al discurso que pronunció desde los balcones de la Casa Rosada (y que fue reproducido en todo el país por radio y televisión), el jefe de Estado casi no se refirió a la supuesta conspiración golpista. Dijo, en cambio, que la principal amenaza era la inflación; más precisamente era el hecho de que "la institución de la moneda se ha desvanecido en la Argentina". Restituir su valor exigía imponer una verdadera "economía de guerra"; y advirtió: "todos debemos comenzar a sacar cuentas de lo que eso significa".

En realidad, los argentinos convivían desde hacía mucho con tasas de inflación importantes. En toda la última década los índices anuales habían sido siempre de más de $100 \%$ y eran varias las voces que desde hacía meses advertían sobre las consecuencias que el aumento exponencial de los precios podría tener en el corto plazo para la naciente democracia. En 1983 la inflación había llegado a 343 \% y en 1984 (primer año de la gestión de Alfonsín) a $688 \%$, provocando, en febrero de 1985, la sustitución del primer gabinete económico del gobierno. De esa forma, si bien la multitud que acudió al llamado de Alfonsín se retiró atónita de la Plaza de Mayo por la dirección que habían tomado los acontecimientos, como el propio presidente sugirió en sus palabras, ciertamente, todos tenían elementos para entender de qué se estaba hablando: la "crisis argentina" era sinónimo de desequilibrio monetario; serían necesarias terapias de emergencia para salvar a la nación del abismo.

Poco menos de dos meses después, el 14 de junio, Alfonsín volvió a dirigirse a los argentinos anunciando un amplio plan para "terminar con la inflación y salvar la democracia". Cuando está en juego un sistema político, dijo, "no es posible pensar en gradualismos", se hace necesaria una ver- 
dadera "política de shock". Lo siguió el ministro Juan Sourrouille, que explicó en detalle los principales ejes del plan que se pondría en marcha de inmediato para salvar al país de la crisis: congelamiento general de precios para terminar con la indexación de la economía, sustitución del peso por una nueva moneda nacional, el austral, y revisión de todos los contratos a futuro aplicando una escala de conversión o "desagio".

Siete meses después en el vecino Brasil los acontecimientos argentinos resonaban como algo más que simples ecos. En febrero de 1986, el presidente Jose Sarney y su Ministro de Fazenda, Dílson Funaro, anunciaron "mudanças fundamentais na economia para salvar o país do abismo ao qual era jogado pelo desequilíbrio monetário". Después de aclarar que "as medidas não são cópia de nenhum programa instituído por qualquer outro país" (en obvia referencia a los dispositivos del Plan Austral), Sarney dijo entre otras cosas: "Estamos derrubando os muros da fortaleza inflacionária. Ainda enfrentamos a força dos hábitos há tempos arraigados. Basta lembrar que a inflação faz parte da vida e dos hábitos de nossas novas gerações que não conhecem outra economia senão essa". Nacía el cruzado, una nueva moneda, que junto con otros dispositivos "heterodoxos" más o menos semejantes a los del plan argentino, era presentada como una auténtica "terapia" destinada a salvar a la nación de una "situación terminal".

Sin duda, la eficacia de los anuncios tuvo que ver en parte con la propia retórica y, en particular, con la dramaticidad de la retórica de la crisis que cada plan de estabilización prometía finalmente superar. En el caso de la Argentina, eran accionados los temas centrales de una narrativa que reconocía una profundidad de más de medio siglo: de un lado, el fin de la "excepción argentina" (con toda la ambigüedad que permite el doble sentido de la expresión: excepción como algo cargado de valores positivos y, también, como algo que escapa de la norma); de otro lado, una nueva manifestación de una ya larga decadencia nacional que, a cada día, alejaba a la colectividad de un pasado de esplendor, y colocaba al país frente a la perspectiva casi fatal de su propia disolución. En Brasil, el horizonte de la crisis no era (nunca fue) la disolución nacional, tampoco la pérdida de un pasado de gloria, sino el extravío del rumbo que conduce a la grandeza y cuyo último capítulo (para bien o para mal, ya que refería al reciente periodo autoritario) había sido el llamado "milagro brasilero". Ése fue el motivo central del ministro Funaro en su discurso de lanzamiento del cruzado: recuperar "o caminho das promessas do crescimento brasileiro", la necesidad de "despertar a nação e movimentar suas forças poderosas". 
Si del lado argentino el contenido dramático del anuncio realizado por el presidente Alfonsín de la "economía de guerra", primero, y del Plan Austral, poco después, buscaba movilizar a la población en defensa del sistema político, invocando los fantasmas de la peor experiencia autoritaria de la Argentina moderna, los términos del presidente Sarney fueron mucho menos apelativos; pero la dimensión dramática estaba implícita en cada uno de sus actos, incluso en el fragmento del discurso de lanzamiento del cruzado en el que se refirió a sus compromisos con la Aliança Democrática (coalición que daba sustento político a su gestión, a la cual había sido arrojado luego de la inesperada muerte de Tancredo Neves que, designado presidente por el Colegio Electoral después del fin del régimen militar, nunca llegó a gobernar). Recordemos que Tancredo Neves fue internado para someterse a una operación abdominal el 14 de marzo de 1985, víspera de su designación como presidente. Murió 38 días después, víctima de una infección generalizada. La historia parecía reforzar el sentido de la tragedia nacional: era 21 de abril, día de Tiradentes, "mártir de la independencia" del Brasil.

Ése era el escenario en el que se abría el ciclo de los planes de estabilización llamados "heterodoxos". Un ciclo que culminaría la década siguiente con el lanzamiento, en la Argentina en 1991, del Plan de Convertibilidad, y en Brasil, en 1994, con el Plan Real (en una pequeña historia poblada de otras marcas, como los eventos hiperinflacionarios de la Argentina, en 1989-90, el Plan Collor en Brasil, en 1991, o los "ajustes" de los planes Austral y Real, conocidos como Planes Primavera y Verano).

De hecho, en las últimas dos décadas del siglo XX la implantación de sucesivos planes de estabilización ganó una verdadera dimensión ritual en esos países. Cualquiera que haya vivido en Brasil o en la Argentina en aquella época no tendrá dificultad en recordar repetidos anuncios por cadena nacional de radio y televisión de congelamientos de precios, ahorros forzosos, cambios de denominación en las monedas corrientes, seguidos de feriados bancarios en los que no sólo los profesionales de la economía, sino también los asalariados, los deudores de cuotas bancarias, los locatarios, los comerciantes, en fin, la mayor parte de los ciudadanos, era expuesta a nuevos dispositivos (desagios, tablitas, "indexadores") que esta vez sí salvarían a la colectividad de la peste de la inestabilidad monetaria. Eran terapias que, como reconocían sus hacedores, buscaban extirpar el mal de la pérdida de valor de la moneda reformulando todos los contratos, interviniendo en todas las relaciones sociales mediadas por dinero. 
Pero para que semejantes imágenes fueran eficaces era necesario también que quienes participaban de la esfera pública tuvieran cierta formación económica. Era preciso que tuvieran los elementos necesarios para comprender y navegar en el mundo de las tecnologías de la desindexación, de las tablitas, de las conversiones monetarias. Era preciso, por fin, que los expertos, autores de esas terapias, gozaran de un cierto crédito público; o más que eso: que fueran verdaderos intelectuales o figuras públicas, reconocidas con la autoridad suficiente para diagnosticar y remediar los males de la nación. Veamos a continuación algunos rasgos de ese proceso de cultivación económica y de transformación de la economía en una lingua fran$c a$ del espacio público, en Brasil y en la Argentina.

\section{Pedagogía de los números y percepciones de las crisis}

Desde el fin de la Segunda Guerra Mundial, y especialmente a partir de los años cincuenta, la pregunta por la naturaleza y los orígenes de la inflación (en ocasiones, aunque no siempre, vista como una dimensión de la cuestión del desarrollo económico) pasó a ocupar un lugar central entre los economistas latinoamericanos o interesados en América Latina. El debate pronto cristalizó en dos escuelas o corrientes mutuamente reconocidas. De un lado, los estructuralistas, que proponían una visión global sobre la articulación entre sectores de la producción, haciendo recaer la responsabilidad principal del aumento de precios en los "estrangulamientos", en especial, del sector agrícola (en otros términos, una perspectiva que acentuaba los problemas de la oferta de bienes). De otro lado, los monetaristas, más cercanos a las visiones ortodoxas o neo-clásicas, que centraban la interpretación del fenómeno inflacionario en la abundancia de dinero (acentuando los efectos del exceso de demanda). La contienda ganó consistencia también gracias a la participación de una serie de figuras que, reconociendo y siendo reconocidas por ambas escuelas, tomaban distancia de éstas, al presentarse como independientes, al tiempo que enfatizaban otras dimensiones del fenómeno inflacionario (como la estructura impositiva, por ejemplo). ${ }^{3}$

3 De lado de los estructuralistas, una de las primeras formulaciones sistemáticas es el texto de Sunkel, O.; "La inflación chilena: un enfoque heterodoxo", El Trimestre Económico, 25(4), 1958; del lado de los monetaristas, Campos, R.: "Two views of inflation", en Hirschman, A., A economia como ciência moral e política, Brasiliense, São Paulo, 1986; entre los varios autores "independientes" puede 
La densidad de la disputa indicaba la existencia de un campo de economistas profesionales relativamente autónomo en diversos países del subcontinente (como la Argentina, Brasil, Chile o México), con instituciones propias de formación y de difusión de teorías y de políticas (incluso varios de los actores del debate ocupaban posiciones centrales en ese campo). La discusión confería también cierto prestigio internacional a algunos de sus protagonistas, al tiempo que en los ámbitos académicos internacionales transformaba a la región en un espacio atractivo, "bueno para pensar" el problema de la inflación. Sin embargo, a pesar de toda la atención dada al desequilibrio monetario, lo cierto es que, como pudo constatar Albert Hirschman dos décadas más tarde, la inflación en América Latina acabó por tornarse "ubicua, prolongándose durante largo tiempo, de modo que hoy [en 1980] parece familiar y casi "normal".".

Reflexionar sobre las causa de esa persistencia es y podrá seguir siendo una obsesión para los economistas. Por su parte, un antropólogo o un historiador interesado en la inflación, no como fenómeno económico sino como un hecho social y cultural, no podrá dejar de atender a una de las dimensiones de la construcción del fenómeno que suele ser considerada por los economistas sólo en el plano de sus luchas internas (esto es, para des-

mencionarse Olivera, J. G.: "Teoría no monetaria de la inflación”, Trimestre Económico, XXXVII, 1960; Olivera, J. G.: "Aspectos dinámicos de la inflación estructural”, Desarrollo Económico 7(27), 1967; Simonsen, M. H.: A experiência inflacionária do Brasil, APEC, Rio de Janeiro, 1964; y Simonsen, M. H.: Inflação: gradualismo X tratamento de choque, APEC, Rio de Janeiro, 1970. Una de las principales puestas en escena del debate tuvo lugar en una conferencia celebrada en enero de 1963, en la Fundación Getúlio Vargas de Rio de Janeiro. Los trabajos allí presentados pueden verse en Baer, W. \& Kerstenetzky, I.: Inflation and growth in Latin America, Irwin, Homewood, 1964. El mejor panorama de la historia anterior de los debates sobre la inflación en América Latina (desde mediados del siglo XIX) es el trabajo de Hirschman, A., De la economía a la política y más allá, Fondo de Cultura Económica, México, 1984, págs. 225-267, sobre el caso chileno. Para el de Brasil, hay elementos útiles en Rangel, I.: A inflação brasileira, Brasiliense, São Paulo, 1963 y Simonsen: A experiência... Para la Argentina en el periodo inmediatamente anterior al aquí tratado, relativo a las políticas anti-inflacionarias del segundo gobierno de Juan Perón, ver Gerchunoff, P. \& Llach, L.: El ciclo de la ilusión y el desencanto. Un siglo de políticas económicas argentinas, Ariel, Buenos Aires, 1998, págs. 195-199 y 208-212); y Berrotarán, P.; Gilbert, J.; Rougier, M.; \& Tenewicki, M.: "La construcción de un problema: los debates en torno a la inflación. Argentina (1940-1952)", en Intelectuales, crisis y cuestión de estado, Argentina 1930 - 2000, Ediciones Al Margen, Buenos Aires, 2004.

4 Hirschman, A: De la economía a la política..., págs. 225-267.

Desde 1960 los índices de inflación anual en Brasil y Argentina fueron siempre de dos dígitos. En la Argentina los porcentajes superaron el $100 \%$ a partir de 1975, con un pico de casi $5000 \%$ en 1989. En Brasil, la inflación se estabilizó en tres dígitos desde 1982, bajó a dos dígitos en el año de implementación del cruzado y alcanzó más de 1000 \% en los años previos al lanzamiento del real. Vale mencionar el principal "padrón de normalidad" de los especialistas: en los Estados Unidos la inflación registró dos dígitos sólo entre 1979 y 1981 (con un máximo de $13 \%$ en ese último año). 
calificar adversarios acusados de ser responsables por la elaboración de modelos defectuosos, o por el fracaso en la implementación de una determinada política). Me refiero a la participación de los propios economistas en la elaboración de una verdadera pedagogía de la economía inflacionaria, de dispositivos y tecnologías que permitieron que las poblaciones (los "agentes económicos") aprendieran a convivir con la inestabilidad monetaria, a defenderse de sus efectos nocivos y, también, a aprovechar las oportunidades abiertas por ella.

Sin duda el período más significativo para observar este proceso de cultivación económica es la década de 1960. Mientras discutían los orígenes y la naturaleza de la inflación y mientras declaraban que el desequilibrio monetario era uno de los peores obstáculos para el desarrollo económico, los especialistas formulaban hipótesis sobre los márgenes de inflación tolerable (algo que no era en modo alguno patrimonio de una u otra corriente). ${ }^{5}$ Al mismo tiempo, países como Brasil y la Argentina experimentaban una verdadera proliferación de indicadores de medición de precios, impulsada por una dinámica que puede reconocerse aun hoy: la implantación de cada nuevo plan de estabilización suele "exigir nuevos y mejores recursos técnicos", al tiempo que los economistas reunidos en instituciones compiten en el mercado de ideas y políticas elaborando y vendiendo índices que serán luego consumidos en la esfera pública económica, cada vez más poblada por boletines de empresas y de asociaciones, por revistas de circulación masiva, por diarios y secciones informativas especializadas (lo que, a su vez, amplía el mercado de trabajo de los profesionales).

Ciertamente la historia de los indicadores de medición de precios es bastante más larga. En la Argentina los index numbers fueron introducidos por Alejandro Bunge en la década de $1920^{6}$. En Brasil, en 1944, la Fundação Getúlio Vargas (FGV) creó el índice más antiguo de los que existen en la actualidad, el IGP-DI. Pero a partir de la década del sesenta se asiste a una verdadera proliferación de indicadores, paralela a la proliferación de instituciones en el campo de los economistas. Algunas de estas ins-

5 Como se sabe, aún en el debate actual quienes se identifican como herederos de las corrientes estructuralistas son partidarios de la introducción de liquidez en el mercado para favorecer el crecimiento económico. Menos evidente es descubrir ese mismo tipo de teoría en la práctica política de economistas identificados con el monetarismo, como Roberto Campos en Brasil o Krieger Vasena en la Argentina (ambos ministros en la década de 1960).

6 Ver Pantaleón, J.: "El surgimiento de la nueva economía argentina: el caso Bunge", en Neiburg, F. \& Plotkin, M. (orgs.), Intelectuales y Expertos. La construcción del conocimiento social en la Argentina, Paidós, Buenos Aires, 2004, págs. 175-202. 
tituciones, como la Fundación de Investigaciones Económicas Latinoamericanas (FIEL) en la Argentina o la FGV en Brasil, fueron también pioneras en implementar estrategias tendientes a difundir por medio de la prensa los indicadores que ellas producían, ofreciendo cursos de formación económica para periodistas. Los index numbers pasaron de esta forma a estar cada vez más presentes en los medios de comunicación, en las nuevas revistas especializadas y no sólo en los recientemente creados suplementos de información financiera, también incluso en las primeras páginas de los diarios de circulación nacional.

La proliferación de indicadores de medición de precios, basada en esta dinámica de expansión del campo de los especialistas, de competencia entre las instituciones que los producían y de difusión y legitimación en el espacio público, considerado por sus fabricadores como un sinónimo de mercado, ocasionó cambios en las formas de percepción del valor del dinero (tal vez sería más correcto decir que acentuó formas antes presentes, otorgándoles modulaciones distintas). Las nuevas tecnologías de medición segmentaron de modo creciente las percepciones del espacio y aceleraron las percepciones del tiempo. Por un lado, índices específicos para mercados específicos (contribuyendo con eso también a dar forma a un fenómeno que los index numbers buscaban simplemente describir: la "segmentación de los mercados"): productos de "primera necesidad", productos "estacionales", productos "escolares", entre muchos otros. Por otro lado, unidades de agregación de variaciones en series temporales cada vez menores ("semanales" o incluso "diarias"), junto a la invención de unidades nuevas como, por ejemplo, entre varias otras, las "cuadri-semanas". Así, paralelamente a la sofisticación de las formas científicas de describir las relaciones entre los precios (de imaginar teorías para explicar los cambios en esas relaciones y modos de conducir o controlar esos cambios), se aceleraba la percepción del tiempo relativa a la dimensión económica de la vida social.

Ahora bien, la proliferación de indicadores de medición de precios fue central en la generalización de una representación eminentemente cuantitativa y numérica del fenómeno inflacionario, coherente con la consagración de ciertas terapias monetarias y de ciertos terapeutas: los "magos de los números", como los presentaba un diario carioca hacia 1986. En Brasil, el inicio de la proliferación de indicadores de medición de inflación puede situarse en las vísperas del golpe de estado de 1964 y reconocerse en la demanda por "más y mejores estadísticas", promovida por la prensa por quienes pedían el fin del gobierno de João Goulart debido, justamente, a su 
supuesta incapacidad para controlar los precios. Resulta fantástico observar con los ojos del presente, educados en una percepción cuantitativa de la inflación, el debate de aquellos años. En Brasil no había entonces índices nacionales "confiables" de medición de precios. El que merecía más crédito, según algunas usinas golpistas, era por ejemplo el índice de inflación del estado de Guanabara (producido por la Fundação Getúlio Vargas y que tenía un ámbito provincial). Eso acentuaba la paradoja: quienes discutían el problema y denunciaban el descontrol del "tigre de la inflación" o los efectos insoportables del "azote del aumento de precios", utilizaban para fundar la denuncia un repertorio de fórmulas cualitativas que revelaba, él mismo, su supuesta incapacidad para conceptuar el fenómeno. Para tratar un mal "vagamente" percibido mediante esas categorías (finalmente, se decía, todo ciudadano brasilero podía "sentir la enfermedad en sus bolsillos") eran necesarios instrumentos de diagnóstico precisos que serían, al mismo tiempo, el principio de la cura.

La difusión de los index numbers y su transformación en una nueva meteorología social, junto a la difusión de las formas de percepción del tiempo operadas por ellos y cada vez más presentes en la vida de las poblaciones integradas al mercado serían centrales en la actualización de la representación de "urgencia" presente en el lanzamiento de cada nuevo "paquete de medidas económicas" o "plan heterodoxo", que tendía, una y otra vez, a salvar países como Brasil y la Argentina de las crisis inflacionarias, transformadas en verdaderas crisis nacionales.

La pedagogía de los números reconocía, también en la década de 1960, otros canales: las acentuadas expectativas de "movilidad social" y expansión del consumo en las crecientes clases medias urbanas, especialmente marcada por la multiplicación de medios de pago: tarjetas de crédito, cheques y sistemas de ahorro y préstamo para la compra de viviendas, automóviles y electrodomésticos (bienes centrales en los padrones de modernidad y confort de los sixties). ${ }^{7}$ Para "estimular el desarrollo", gobiernos, asociaciones de empresas, bancos y agencias de inversión se empeñaron también en la ampliación del mercado de capitales, buscando

7 En la Argentina, las primeras tarjetas de crédito (LondonCard) fueron publicitadas en octubre de 1969. En Brasil, la utilización del cheque para pagos corrientes (algo ciertamente original desde un punto de vista comparativo) comenzó a generalizarse también hacia fines de la década de 1960. Para una visión de la expansión del mercado del consumo en la Argentina, en un periodo anterior, ver por ejemplo Rocchi, Fernando: "Consumir es un placer: la industria y la expansión de la demanda en Buenos Aires a la vuelta del siglo pasado", Desarrollo Económico, 37 (148), 1998. 
no sólo que las empresas medianas y pequeñas cotizaran en la Bolsa, sino también que los títulos privados y públicos fueran comprados por individuos que aprendían a invertir en valores para "ganarle" a la inflación. Así, desde finales de los años cincuenta se expandieron las campañas para atraer inversores a la Bolsa, se diversificaron las hojas de información financiera distribuidas en las cities de Buenos Aires o São Paulo y fueron editados nuevos "manuales del buen inversor" para no especialistas. ${ }^{8}$

Por otra parte, al mismo tiempo en que insistían en denunciar la calamidad del aumento de precios, y diseñaban e implementaban sucesivos planes de estabilización, los profesionales encargados de la gestión estatal de la economía ponían en funcionamiento dispositivos que difundían la cultura de la inestabilidad monetaria. Dos ejemplos ilustran este proceso. El primero: en la Argentina, en julio de 1962, el ministro de economía, Álvaro Alsogaray, en un discurso emitido por Cadena Nacional de Radio y Televisión después de anunciar que "el país enfrenta la más grave crisis económica de su historia reciente" comunica el lanzamiento del "Empréstito Nacional 9 de Julio", un título público que "no sufrirá los efectos de la inflación". El ministro convoca a que "en cada ciudad, en cada pueblo, en cada escuela, en cada fábrica, en una palabra en cada lugar en donde se reúnan voluntades argentinas, se organicen comisiones, se discuta, se estimule y se desarrolle la idea del empréstito". ${ }^{9} \mathrm{Y}$ anuncia que se espera que pronto los comercios y los empresarios acepten recibir y pagar deudas no en moneda corriente, sino en esos títulos. Pocas semanas después se establece que los empleados públicos reciban partes de sus salarios en "Títulos 9 de Julio". Así sucede por algunos meses, hasta que cerca de fin de año Alsogaray renuncia a su puesto.

El segundo ejemplo remite al "Programa de Ação Econômica do Governo" (PAEG) puesto en marcha en Brasil en 1964, bajo la gestión militar del mariscal Castello Branco y elaborado por Otávio Gouveia de Bulhões y Roberto Campos. El PAEG dio inicio a un proceso de indexación institucionalizada que no tuvo paralelo en otros contextos nacionales, con la invención de la llamada "correção monetária" y con la disposición de reajustes de contratos y salarios según las variaciones de una moneda

8 Como, en Argentina, entre otros, el libro de Alemann, Juan: La inversión bursátil, selección contable, Buenos Aires, 1956. En términos más institucionales fueron promovidos seminarios nacionales del "Programa para el desarrollo del mercado de capitales", organizados por el Centro de Estudios Monetarios Latinoamericano (CEMLA), creado en 1952 por los Bancos Centrales del continente.

9 Diario El Cronista Comercial, 10 de julio de 1962, pág. 1. 
virtual que tendría larga vida en el país: las Obrigações Reajustáveis do Tesouro Nacional (ORTN). ${ }^{10}$ Estos sistemas de indexación, que se generalizarían en el país a partir de entonces, sintetizaban el doble papel de los index numbers ya mencionado: eran al mismo tiempo instrumentos de diagnóstico y de cura. Y, cuando exitosos (esto es: cuando servían para regular eficazmente contratos futuros), los indicadores se asemejaban a las ambiguas funciones del propio dinero en las sociedades de mercado porque estaban al mismo tiempo dentro y fuera del juego del intercambio, y eran al mismo tiempo medidor de valores y portador de valor. ${ }^{11}$

El hecho de que dispositivos semejantes hayan tenido menos continuidad en la Argentina ciertamente indica algo de la menor densidad de la esfera estatal en este país respecto de Brasil. Pero más que eso (y teniendo en cuenta que con las comparaciones en el plano de las culturas de la economía es preciso ser muy cuidadosos), interesa notar que en la construcción de mecanismos de interiorización de la inestabilidad monetaria puede ser tan eficaz la relativa continuidad en la implementación de una política, como la implementación de una serie de políticas heterogéneas y discontinuas que obligan a los agentes económicos a aprender permanentemente nuevas "reglas de juego". Por otra parte, no todo se juega en el plano de las políticas públicas (como muestra la proliferación de medios de pago, el mercado ciertamente "actúa" con relativa autonomía), ni, en fin, todo se restringe al universo de las reglas (como se sabe, en ocasiones son éstas las que acaban incorporando hábitos que los agentes económicos desarrollan para burlarlas).

De cualquier manera, lo dicho hasta aquí basta para sustentar una de las ideas centrales de este artículo: la inestabilidad monetaria tuvo siempre como uno de sus artífices a los profesionales de la economía. Un resultado de la contribución de estos especialistas a la construcción social de la inestabilidad monetaria puede verse en las carreras académicas, políticas y en ocasiones empresariales o financieras, nacionales e internacionales de varios de ellos. Otro resultado se constata en la transformación del lenguaje de la economía monetaria en una dimensión del sentido común de amplias capas de las poblaciones urbanas de países en los que la inflación acabó por

10 Para un análisis contemporáneo de este proceso ver Gudin, E.: "A institucionalização da inflação", Digesto econômico 163, 1967.

11 Esta aproximación entre el uso y el sentido de los indicadores y del dinero se inspira en Simmel, Georg: La philosophie de l'argent, PUF, Paris, 1997. Especialmente el capítulo 1. Sobre la confianza pública en los números y la construcción de "números sociales", ver la obra de Porter. 
ser, en las palabras ya citadas de Hirschman, "algo familiar y casi normal"; modelando las formas de imaginar el futuro de cada país y sus crisis.

\section{Gradualismo y shock: terapias y debates públicos}

La identificación de desequilibrio monetario y crisis nacional, en la década de 1980, estuvo asociada al ascenso social de nuevos especialistas: los economistas profesionales, transformados en verdaderos intelectuales públicos, protagonistas de primer orden de la gestión estatal. Ése era el caso de los "terapeutas del austral", como fue conocido el plan para estabilizar que impuso esa nueva moneda en la Argentina, en 1985. Al contrario de quienes habían gestionado las políticas económicas del partido que entonces gobernaba el país (como el primer ministro de economía de Raúl Alfonsín, Bernardo Grinspun, que era contador). Después de graduarse en la Universidad de Buenos Aires, varios habían obtenido sus doctorados en Estado Unidos (José Luis Machinea en Minnesota, Daniel Heymann en California, Mario Brodersohn en Harvard, Adolfo Canitrot en Stanford), con tesis que trataban más o menos directamente sobre la inflación desde perspectivas no monetaristas, y enriquecían, de esa manera, las elaboraciones de varios profesores de relativo prestigio en los Estados Unidos sobre la inestabilidad monetaria y el crecimiento económico en los países subdesarrollados..$^{12}$ Sólo el ministro Sourrouille había ocupado antes altas funciones en el campo estatal (como primer director del Instituto Nacional de Estadísticas y Censos, INDEC, fundado en 1968). ${ }^{13}$ También había vivido un periodo en los Estados Unidos, trabajando en Harvard junto al latinoa-

12 Fue el caso del integrante más joven del equipo, Heymann, que defendió su tesis en UCLA bajo la supervisión de Axel Leijonhufvud, que en esa época era un profesor de gran prestigio pero, como neo-keynesiano, un outsider. Snowdon, B.: "Outside the mainstream: an interview with Axel Leijonhufvud”, Macroeconomic Dynamics 8 (1), 2004, págs. 117-145. Su interés en comprender contextos de extrema inestabilidad monetaria fuera del marco de la teoría del equilibrio general lo hacía (en palabras de Heymann, en entrevista con F. Neiburg, Buenos Aires, el 11 de noviembre de 2003) especialmente atractivo para estudiantes oriundos de países con tradición inflacionaria y que, por razones teóricas e ideológicas, preferían no realizar sus doctorados en departamentos de economía identificados con el mainstream monetarista. Buscaban modos de combatir la inflación sin implementar políticas regresivas en términos de ingreso y empleo. La asociación entre profesor y alumno acabó rindiendo varios frutos, como puede verse en Heymann, D. \& Leijonhufvud, A.: High Inflation, Oxford University Press, Oxford/ New York, 1995, donde, entre otras, se revisa la experiencia en los años ochenta de la Argentina, Bolivia, Brasil, Israel, México y Perú.

13 Aunque antes o después de volver de Estados Unidos casi todos ellos se habían desempeñado como técnicos en instituciones estatales (como el propio INDEC o el Consejo Nacional de Desarrollo, CONADE). 
mericanista Richard Mallon. Ambos se conocieron en la CEPAL, en Chile, ${ }^{14}$ lo que apunta a otro de los ejes que estructuran esa red de individuos (una experiencia compartida por otro de sus miembros, Roberto Frenkel): la participación en el circuito latinoamericano que transitaba entre la CEPAL (en Santiago y en sus filiales), y otras agencias internacionales y centros académicos con sede en los Estados Unidos. En la Argentina, dos instituciones fueron centrales para esas articulaciones, que proyectaban a sus integrantes en la escena política y académica local: el Centro de Investigaciones Económicas del Instituto Torcuato Di Tella, y el Instituto de Desarrollo Económico y Social (IDES), creados respectivamente en 1958 y 1960. ${ }^{15}$ Durante la dictadura militar que antecedió a la llegada de estos jóvenes a las más altas posiciones de la gestión estatal de la economía, especialmente el IDES (casi todo ese periodo bajo la dirección de Sourrouille) se convirtió en un think tank por el que pasaron los creadores y gestores del Plan Austral.

Retrospectivamente, vale la pena imaginar la singular excitación intelectual de estos money doctors cuando las vicisitudes de la política los colocó frente a la posibilidad de ejercitar su saber para salvar al país y la democracia. ${ }^{16}$ Un puñado de individuos se reunía horas y horas durante días y noches, en la semi-clandestinidad, pues buena parte del éxito del plan se jugaba en llegar al "día D" sin que los detalles fuesen conocidos por los mercados. ${ }^{17}$ Apasionados por su profesión, desarrollaban una original experiencia de laboratorio, especulando sobre la cultura económica de la población (que debía "creer" en las medidas), preparando hasta los detalles más sutiles de los dispositivos que "rediseñarían la totalidad de la vida de las personas" y que, factor central para su éxito, debían ser anunciados en el momento justo.

Durante los meses previos al lanzamiento del austral la inflación se aproximaba, sin llegar en efecto, al $30 \%$ mensual. El “día D” sería el de la

14 Entrevistas a J. Sourrouille de F. Neiburg, Buenos Aires, el 7 de octubre y el 6 de noviembre de 2003

15 En Neiburg y Plotkin: Intelectuales y Expertos... estudiamos la importancia de estas instituciones y la confluencia de estos circuitos de teorías y políticas económicas en la construcción de la "nueva economía" argentina de la segunda mitad del siglo XX.

16 Aparte de las ya citadas entrevistas con Heymann y Sourrouille, este relato se basa también en entrevistas realizadas, todas en Buenos Aires, por F. Neiburg a Roberto Frenkel (el 19 de noviembre de 2003) y Adolfo Canitrot (el 27 de noviembre de 2003); y por F. Neiburg y M. Plotkin a Pablo Gerchunoff (el 14 de septiembre de 2003).

17 En Bresser Pereira, L. C. \& y Nakano, Y.: "Inflação inercial e choque heterodoxo no Brasil", en Rego, J.M. (org.), Inflação inercial, teorias sobre inflação e Plano Cruzado, Paz e Terra, Rio de Janeiro, 1986, Bresser y Nakano han tematizado la cuestión del "día D” para la aplicación de planes heterodoxos tipo austral o cruzado. 
realización (en el sentido literal de hacerse real) de ese número mágico de $1 \%$ al día. Cuando los especialistas consideraron que ese coeficiente finalmente se había trasladado de las "cabezas" a las prácticas y la pérdida del valor de la moneda pareció estabilizarse en ese porcentaje, el plan fue efectivamente anunciado. ${ }^{18}$

Pocas semanas antes, algunos de los integrantes de aquel singular laboratorio en el que se preparaba el austral habían viajado a Washington (casi clandestinamente, según recuerdan, en días y por rutas diferentes) para presentar los detalles del proyecto a las máximas autoridades del Fondo Monetario Internacional, Banco Mundial y Federal Reserve. Aunque tensa, la reunión parecía envuelta en un clima de familiaridad, propio del encuentro entre viejos conocidos, poseedores de una misma cultura académica y económica. Unos y otros reproducían una relación en la que cada uno sabía ya su papel: estudiantes latinos debían demostrar seguridad en inglés y en sus gestos, honrar su fama de jóvenes brillantes y tornar convincentes los proyectos heterodoxos que, por primera vez, serían puestos en práctica. Los profesores dieron su aprobación. En realidad, no era la primera vez que escuchaban ideas semejantes. Hacía tiempo que circulaban en agencias internacionales, think tanks y departamentos de economía de ciertas universidades norteamericanas. Incluso, a comienzos de diciembre de 1984 había tenido lugar en Washington una conferencia patrocinada por el Institute for International Economics en la que fueron discutidas formas de terminar con la "inflación inercial", en especial, en la Argentina, Brasil e Israel. ${ }^{19}$ Un mes después de anunciado el Austral, sería lanzado un plan con aspectos semejantes en Israel. Siete meses más tarde Brasil entraba en la era del cruzado. Entre quienes participaron en esa conferencia había dos individuos que integrarían el equipo que diseñó el plan de estabilización aplicado en este último país: Pérsio Arida y André Lara-Resende.

Aunque las distintas reconstrucciones del debate que llevó a la implementación del Plan Cruzado pueden trazar genealogías diferentes,${ }^{20}$ todos los autores reconocen un carácter pionero en el libro Inflação: gradualis-

18 Es interesante notar el carácter mágico de esos números pues, estrictamente hablando, el 1 $\%$ al día resulta en un porcentaje mensual acumulado de inflación superior a $30 \%$.

19 Los trabajos fueron publicados en marzo de 1985 por el MIT en Williamson, John: Inflation and Indexation: Argentina, Brazil and Israel, MIT Press, Cambridge, 1985.

20 Por ejemplo Arida, P.: Inflação Zero. Brasil, Argentina, Israel, Paz e Terra, Rio de Janeiro, 1986, Bresser Pereira, L. C.: "Inflação inercial e Plano cruzado", Revista de Economia Política, 6 (3), 1986, pág. 9-24; y Rego, J. M. (org.): Inflação inercial, teorias sobre inflação e o Plano cruzado, Paz \& Terra, Rio de Janeiro, 1986. 
mo X tratamento de choque, publicado por Mario Henrique Simonsen en 1970. La razón de semejante unanimidad tal vez se encuentre menos en su contenido (ya que el autor buscaba un término medio entre las posiciones) y más en el hecho de que Simonsen era uno de los héroes modernizadores de la economía brasilera, entre otras cosas uno de los fundadores y el primer director de una institución, creada en la década del sesenta, que se había tornado central en el campo de los economistas, la Escola de PósGraduação em Economia (EPGE, Fundação Getúlio Vargas, Rio de Janeiro), por la que pasaron varios heterodoxos de los ochentas. ${ }^{21}$

Dos de ellos, André Lara-Resende y Francisco Lopes, habían completado sus maestrías en la EPGE antes de trasladarse a los Estados Unidos para obtener sus doctorados (en el MIT y en Harvard, respectivamente). A su regreso al país, se integraron al recién creado Departamento de Economía de la Universidade Católica do Rio de Janeiro (PUC-RJ). Sus organizadores, Pedro Malan y Dionisio Dias Carneiro, habían encabezando una escisión entre quienes rodeaban a Simonsen en la EPGE, cuando éste se integró al gobierno del general Geisel como Ministro de Planejamento. Militantes a favor de la democracia y, al mismo tiempo, fuertes en economía matemática y con un alto capital de relaciones internacionales, los jóvenes economistas de la PUC encarnaban como ningún otro un grupo singular al que no demoraron en integrarse otros individuos que tendrían papeles claves en el cruzado, como Pérsio Arida, formado en la Faculdade de Economia e Administração de la Universidade de São Paulo (FEA-USP), que había pasado un periodo en Princeton y otro, en el que coincidió con Lara-Resende, en el MIT. ${ }^{22}$

Desde inicios de los años 1980 la PUC-RJ se transformó en una usina de elaboración y de divulgación de nuevas teorías y planes de estabilización; el Plan Cruzado fue el primero de ellos. Por allí pasaron varios economistas de renombre y también algunos jóvenes latinoamericanos

21 Simonsen fue también colaborador de Roberto Campos en la implementación del PAEG, ministro del general Geisel y miembro del directorio de varias empresas y bancos (ver la entrevista a Simonsen, en Biderman, C.; Cozac, L. F. \& Rego, J. M., (orgs.): Conversas com Economistas Brasileiros, Editora 34, São Paulo, 1996, págs.189-211).

22 Arida obtuvo su doctorado en el MIT recién en 1992, lo que en nada afectó su reputación de "joven brillante". Edmar Bacha, doctorado en Yale y por un tiempo profesor de la EPGE, fue otro de los reclutados por la PUC que participaría en el cruzado. Sobre las trayectorias sociales e intelectuales del Departamento de Economía de la PUC-RJ (fundado en 1977), ver Loureiro, M. R.: Os Economistas no Governo, Fundação Getulio Vargas, Rio de Janeiro, 1997, págs. 65-95 y Dezalay, Y. \& Garth, B.: The Internationalization of Palace Wars: Lawyers, Economists, and the Contest to Transform Latin American States, University of Chicago Press, Chicago, 2002, págs. 100-103. 
- entre éstos, uno de los futuros hombres del Austral, el ya mencionado Roberto Frenkel..$^{23}$ A partir de 1984, junto con el final del gobierno militar, dos trabajos en particular ganaron cierta notoriedad. Ambos postulaban la necesidad de acabar con la "inflación inercial", esto es, con el mecanismo por medio del cual el aumento de precios se transforma en un proceso autónomo, impulsado por los agentes económicos que actúan buscando reproducir la tasa de inflación y los picos de sus ganancias reales pasadas. $\mathrm{La}$ teoría confirmaba el éxito social de los index numbers y de todas las tecnologías de la indexación ensayadas en las últimas décadas, en las que, como vimos, los números se habían transformado, de hecho, en objeto de confianza pública.

Las soluciones propuestas tenían distintos énfasis. Podía argumentarse en favor de un periodo de congelamiento de precios ${ }^{24}$, o proyectar un sofisticado mecanismo de transformación de los "indexadores" (con los que, como ya fue mostrado, los brasileros convivían hacía ya dos décadas) en moneda corriente. Era justamente el paper presentado en la conferencia de Washington por Arida y Lara-Resende (1985) y que, conocido como "propuesta Larida", circulaba en Brasil a instancias del propio Simonsen, que daba así su padrinazgo al proyecto de estos jóvenes, a pesar de las diferencias teóricas y políticas que mantenía con ellos desde hacía una década. ${ }^{25}$

Algunos contrastantes entre los procesos de legitimación de las heterodoxias en Brasil y la Argentina son bastante sugestivos y contribuyen a dotar de tonos singulares las percepciones de la crisis, de la inflación y sus terapias en cada país, acentuando imágenes de continuidad y futuro, en el caso brasilero, y del carácter terminal y de ruptura, en el argentino. El primer contraste se refiere a las relaciones entre generaciones de especialistas, siempre más marcadas por quiebres en el segundo país que en el primero. Los brasileros podían citar en sus papers una constelación ecléctica de profesores (el propio Simonsen, Rangel, Furtado, o Delfim Netto, por ejem-

23 Un artículo de Frenkel (dedicado al análisis de los mecanismos de decisión de precios en contextos de alta incertidumbre o hyperstagflation), publicado en 1979 en la revista del IDES, fue integrado al sistema de referencias corrientes del grupo brasilero.

24 Lopes, F.: Choque heterodoxo. Combate à inflação e reforma monetária, Campus, Rio de Janeiro, 1984.

25 Los bastidores de la elaboración del Plan Cruzado son conocidos, han sido reconstruidos por periodistas (en especial, Sardenberg, C. A.: Aventura e agonia: nos bastidores do cruzado, Companhia das Letras, São Paulo, 1987) y fueron relatados por los propios protagonistas, por ejemplo,, en las entrevistas a Bacha, Gonzaga Belluzo, Lara-Resende y Arida publicadas en Biderman: Conversas com ... y a Cardoso de Mello, Sayad y Lopes publicadas en Mantega \& Rego: Conversas com... 
plo), algo casi impensable entre sus colegas argentinos (con la única eventual excepción de Julio Olivera, un reconocido académico que nunca fue alto funcionario del Estado, ni tuvo participación de relieve en la empresa privada). ${ }^{26}$ Eso a su vez indica padrones diferentes de relaciones entre los segmentos de las elites intelectuales y políticas: ciertamente ninguno de los jóvenes economistas democráticos argentinos reconocería el padrinazgo (o aun algún mérito intelectual) en cualquier funcionario del gobierno militar anterior, como sí podían hacerlo sus amigos brasileros. Por fin, aunque las biografías sociales de ambos grupos muestran varios paralelismos (como trayectos de ascenso social a través de la profesionalización y del pasaje por los Estados Unidos), entre los brasileros predominaba una proximidad mayor a las elites que siempre se mostraron más cohesionadas (algo ciertamente característico de una sociedad más diferenciada y menos plebeya que la Argentina). ${ }^{27}$

A todo eso se debe agregar el hecho de que las teorías heterodoxas tuvieron otros focos de producción (no sólo la PUC-RJ), que gozaban también de gran prestigio intelectual y buenas articulaciones con el campo político y económico. Otro de esos focos era la Escola de Administração de Empresas de la Fundação Getúlio Vargas de São Paulo (EAESP) y la Revista de Economia Política, fundada en 1981 por Luis Carlos Bresser Pereira. Profesor de la EAESP y de la Facultad de Economia e Administração de la USP (FEA), donde obtuvo su doctorado (luego de un MA en Michigan), Bresser había sido alumno de otro de los héroes modernizadores de la economía brasilera y hombre fuerte del régimen militar: Antonio Delfim Netto. La revista de Bresser fue uno de los medios más dinámicos de difusión de las "tesis inercialistas" (de las que según varios comentadores tenía cierta razón en reclamarse precursor). ${ }^{28}$ Otro factor impensable para sus amigos argentinos: mantener una relación de cierta

26 Incluso el propio Raúl Prebisch, creador del Banco Central argentino, en 1935, y de la CEPAL, en 1948, nunca fue una unanimidad en su país.

27 Vale recordar que entre los "ingeniosos padres del cruzado" había algunos auténticos "herederos", como Francisco Lopes, hijo de Lucas Lopes, entre otras cosas presidente del BNDE y Ministro da Fazenda. También, algo raro entre los argentinos, varios de ellos estaban casados con hijas de "grandes familias" de la elite brasilera (un elemento importante en ese universo altamente masculino de los gestores de la política económica).

28 Ver, por ejemplo, Bresser-Pereira \& Nakano: "Inflação inercial...” y Rego, J. M. (org.): Inflação inercial, teorias sobre inflação e o Plano cruzado, Paz \& Terra, Rio de Janeiro, 1986. Como se sabe, Bresser no demoraría en tener la oportunidad de poner en práctica sus ideas, cuando en julio de 1987 substituyó a Dilson Funaro al frente del Ministro de Fazenda (lanzando la "segunda fase" del Plan Cruzado, conocida como "Plano Bresser"). 
proximidad con Delfim Netto y, al mismo tiempo, fundar una revista que tenía (y tiene) como "patronos" a figuras que, identificadas con el progresismo, merecen un respeto teórico unánime entre los economistas brasileros de las varias corrientes: Caio Prado Jr., Celso Furtado e Ignácio Rangel.

Algo común a los heterodoxos de São Paulo y de Rio de Janeiro era, asimismo, relativamente más escaso entre los argentinos, una trayectoria continua en los medios empresariales y financieros y en la burocracia de gobierno, aun durante el periodo militar al que se oponían. ${ }^{29}$ Así, a sus articulaciones académicas y políticas intergeneracionales los brasileros podían sumar un alto capital de credibilidad, fundado en la proximidad con el mercado y con el Estado. ${ }^{30}$

Pero hay otro contraste que merece mayor atención aquí, pues remite a lo que un poco exageradamente tal vez podría llamarse "difusión de la cultura económica en tiempos de crisis": del lado argentino, como vimos, el relato de un seminario académico semi-clandestino; del lado brasilero, una intensa participación en discusiones públicas. Es verdad que la contraposición debe acreditarse más a un registro de grados y de énfasis: los detalles del plan brasilero fueron también elaborados en secreto (recordemos la importancia del "día D") y en la Argentina había igualmente una sensación de inminencia antes de los anuncios. También es verdad que es necesario tomar en cuenta la cronología, el hecho de que los planes argentino e israelí fueron lanzados primero que el cruzado. En suma, aun con todas esas precauciones, el contraste sugiere una escala y una intensidad sensiblemente mayor de la esfera pública económica en Brasil. ${ }^{31}$

De hecho, en el periodo que pasó entre el lanzamiento del austral y el anuncio del cruzado la experiencia de los vecinos (que pronto había

29 Algunos participaban en la Fundação Instituto de Pesquisas Econômicas (FIPE), creada en 1973 en la FEA-USP y que representaba de modo ejemplar la articulación de los nuevos profesionales de la economía con la modernización del campo económico en la época del "milagro brasilero"; otros publicaban regularmente en la importante revista Pesquisa e Planejamento Econômico, del Instituto de Pesquisa Econômica Aplicada (IPEA), perteneciente al Ministerio de Planejamento.

30 Entre los creadores del austral, sólo Brodersohn tenía características semejantes. Loureiro ha llamado la atención para una regularidad que vale para los economistas brasileros que llegaron a la adultez a inicios de los años ochenta: su pasaje por la consultoría de grandes empresas como una escala previa a la gestión política. Loureiro: Os Economistas..., págs. 90-94.

31 La mayor dinámica de la esfera pública económica en Brasil que en la Argentina en esa época contrasta a su vez con la historia de la disciplina en cada país: en la Argentina la primera Facultad de Ciencias Económicas fue fundada en 1913 y hacia el fin de esa década ya había dos revistas académicas de importancia (la Revista de Ciencias Económicas y la Revista de Economía Argentina). En Brasil, la primera Facultad de economía fue creada recién en 1946 (un año después, fue lanzado la Revista Brasileira de Economia, primera publicación del género en el país). 
comenzado a dar señales de debilidad) fue ampliamente debatida en Brasil, en publicaciones de tinte más académico, ${ }^{32}$ en ámbitos periodísticos (como ISTOÉ, Exame o Gazeta Mercantil ${ }^{33} \mathrm{y}$ en medios empresariales, que reflejó no sólo la escala, la institucionalización y la continuidad del campo de los economistas en este país sino también una rara certidumbre: antes de ser anunciado, el plan heterodoxo brasilero parecía ser aceptado como un hecho aun por los economistas más identificados con la ortodoxia. Figuras como Delfim Netto, o el propio Simonsen, admitían que era la hora de los más jóvenes, y reconocían méritos en las ideas heterodoxas (aunque expresando diferencias o exigiendo revisiones, principalmente en cuanto al congelamiento de precios)..$^{34}$

Por otra parte, otros grandes nombres de la generación anterior, ligados al estructuralismo y al desarrollismo (como Celso Furtado), mantenían relaciones de estrecha proximidad con el tercer foco de gestores del Plan Cruzado, integrado por figuras como Luiz Gonzaga Belluzo, Jõao Manuel Cardoso de Mello, y Maria da Conceição Tavares, enrolados en instituciones académicas que ocupaban posiciones reconocidamente diferentes a las de la PUC-RJ, la EPGE o la EAESP, como el Departamento de Economía de la UNICAMP y el Instituto de Economía de la UFRJ. ${ }^{35}$ A los ojos de los argentinos, el cruzado no podía sino aparecer como resultado de una rara confluencia entre individuos de trayectorias variadas y de legitimidades políticas y académicas contrastantes; una percepción bien fundada, si atendemos al esbozo aquí propuesto de las configuraciones diferenciales en las relaciones entre intelectuales (economistas) y elites estatales en cada país.

32 Por ejemplo, Bresser Pereira, L. C.: "Como a Argentina acabou com sua inflação inercial", Gazeta Mercantil, 17 de julho, 1985, pág. 4 y Modiano, E.: "O choque argentino e o dilema brasileiro", Revista de Economia Política 6 (2), 1986.

33 En realidad ya en diciembre de 1984, bastante antes del austral, Lara-Resende había publicado una serie de artículos en Gazeta Mercantil proponiendo una "moneda indexada" para "romper o frustrante imobilismo a que está relegada a política anti-inflacionária". Lara-Resende, A.: "A moeda indexada nem mágica nem panacéia", Gazeta Mercantil, 26, 27 e 28 de setembro, 1984. En una línea semejante, Arida publicó otro texto en el mismo diario, en octubre en Arida, P.: "Economic Stabilization in Brazil", Working Paper, No. 149, Woodrow Wilson International Center for Scholars, Washington, 1984, y un artículo en inglés en el Woodrow Wilson International Center for Schollars en Arida, P.: "A ORTN serve apenas para zerar a inflação inercial”, Gazeta Mercantil, 19 de outubro, 1984.

34 Aunque manifestando reservas, Delfim Netto en un primer momento no dudó en calificar a sus autores de "brillantes" (ISTOÉ, 5/3/1996: 20-21). Ver también Delfim Netto, Antonio: "Alfonsin substitui demagogia por coerência", Revista de Economia e Política 5(4), 1985 y el artículo de LaraResende: "A moeda indexada...".

35 Otro de los gestores del plan, João Sayad, había hecho carrera en la FEA-SP. 
Cuando el 28 de febrero de 1986 el presidente Jose Sarney anunció a los "brasileiros e brasileiras" las "mudanças fundamentais na economia" que se instituían a partir de ese día para "tirar o país da crise", el Ministro de Fazenda, Dílson Funaro, anunció los fundamentos conceptuales de la reforma:

"A inflação brasileira se desgarrou dos fatores originais que a impulsionaram. Passou a extrair forças do seu próprio movimento. A existência da correção monetária, aplicada de forma generalizada sobre os valores contaminou a psicologia de todos os agentes econômicos e marginalizou o cruzeiro em suas funções monetárias. Todos começaram a fazer os cálculos dos seus rendimentos e de seu patrimônio em ORTN". ${ }^{36}$

Rara magia la de la ciencia económica que consigue reproducir términos tan semejantes en anuncios dirigidos a públicos tan diversos: aquí, la población de un país, allí un grupo selecto de especialistas. Lo cierto es que la aproximación entre ambos públicos era el resultado de un lento proceso al cabo del cual los intérpretes de la crisis, que eran los cerebros de la teoría de la inflación inercial y de las técnicas del desagio, se habían convertido en verdaderos intelectuales públicos. De hecho, casi al mismo tiempo en que era anunciada la reforma monetaria, los brasileros bien informados podían leer las obras que presentaban la teoría que le servía de fundamento. Así, por ejemplo, sólo dos meses después de lanzado el plan y con el título "Garantia na embalagem" el semanario ISTOÉ (25/8/1986) difundía la reseña de dos volúmenes recientemente publicados: Choque heterodo$x o^{37}$ e Inflação Zero ${ }^{38}$. También informaba, al pasar, la decisión de sus autores de pedir a las editoras Campus y Paz \& Terra que imprimieran el valor de los libros en la tapa, como "garantía de estabilidad", algo inusual en la época dado el permanente aumento de precios.

\section{Conclusión}

La articulación entre la narrativa económica erudita y las culturas de la economía, difundidas en la esfera pública e incorporadas en forma de disposiciones por los individuos, opera en buena medida a través de imá-

36 Los discursos han sido tomados de "Plano de estabilização (documentos)", Revista de Economía e Política 6 (3), 1986: págs. 112-115.

37 Lopes: Choque heterodoxo...

38 Arida: Inflação Zero... 
genes y metáforas relativas a la naturaleza, centrales en las representaciones de las crisis que han servido para justificar la aplicación de planes de estabilización monetaria ${ }^{39}$ El vocabulario de la crisis monetaria se lo puede equiparar a un vocabulario médico. Describe el mal en términos de la propagación de una "enfermedad" que, tratada con retardo o inadecuadamente, puede merecer el adjetivo de "terminal". Nada de extraño hay en que así sea en sociedades como las nuestras, donde el dinero es el principal mediador de las relaciones entre las personas mismas, y entre las personas y los objetos, y también un valor en sí mismo, central en la definición del estatus y la identidad de las personas. En semejante mundo social, la pérdida de valor, o la incertidumbre respecto del valor de la moneda, no puede sino ser sinónimo de vértigo colectivo.

Pero si la historia de la asociación entre inflación y enfermedad posee una duración tan larga como la propia modernidad, ${ }^{40}$ no sucede lo mismo con las formas contemporáneas, eminentemente cuantitativas de conceptuar la inflación, asociadas al uso generalizado de los números, a la legitimación social de la economía matemática y a la transformación de los money doctors en intelectuales públicos. ${ }^{41}$ Con las representaciones cuantitativas de la inflación sucede algo semejante a la "pasteurización de la sociedad", descrita por Bruno Latour como un efecto del descubrimiento del carácter nocivo de esas entidades nuevas llamadas microbios. Las teorías y sus objetos escapan de los laboratorios, invaden la vida cotidiana de las personas que pasan a observar sus cuerpos a través conceptos híbridos, que mezclan formas antiguas y nuevas de concebir la salud y la enfermedad. ${ }^{42}$

Importa señalar la relación circular que en el sentido común, o en la cultura, mantienen las formas cuantitativas de conceptuar el desequilibrio monetario (cuyo principal instrumento son los indicadores) y las tecnologías y terapias monetarias (como los mecanismos de indexación y desagio, o las tablas de sustitución de monedas nacionales). Para que éstas sean eficaces (nadie lo sabe mejor que los propios economistas) deben ser "confiables" a los ojos de los agentes económicos. Y para ser confiables, deben,

39 Para una reflexión general sobre el lugar de las imágenes naturales en la legitimación de las teorías económicas, ver la obra de Mirowski

40 Las teorías de Nicolás de Oresme, que asocian la inflación y la peste en la Francia del siglo XIV son, ciertamente, un punto de inflexión en semejante construcción.

41 Sobre la aparición de la categoría money doctor en América Latina hacia finales del siglo XIX, ver Drake, P. W.: Money doctors, foreign debts, and economic reforms in Latin America from the 1890s to the present, SR Books, Wilmington, 1994.

42 Latour, B.: The Pasteurization of France, Harvard University Press, Cambridge, Mars 1988. 
entre otras cosas, ser comprendidas. De allí que en el lanzamiento de cada plan de estabilización, tan importante como los técnicos idealizadores de las tecnologías hayan sido siempre los comunicólogos encargados de explicarlas y traducirlas al lenguaje ordinario. Los legos, por su parte, poseen un banco de conocimientos que permite no sólo decodificar las tecnologías terapéuticas sino también defenderse y explotar las posibilidades abiertas por los periodos de crisis inflacionaria. ${ }^{43}$ Esa larga cultivación monetaria, que permite a los individuos conceptuar y navegar en las crisis, se ha favorecido también de los ciclotímicos periodos de expansión económicas, asociados a expresiones como "milagro" (en Brasil) o "plata dulce" (en la Argentina). Ésas han sido experiencias cruciales en el aprendizaje de las distinciones y la manipulación de índices, de las posibilidades abiertas por el paso de una a otra forma de crédito, contando, de antemano muchas veces, con la pérdida de valor de las monedas, o con la conversión entre monedas, indexadores y contratos. Ejercicios tan sofisticados y tan difundidos, que merecieron la atención de más de un visitante extranjero, admirado por la alta cultura monetaria de sus anfitriones brasileros y, especialmente, tal vez, argentinos, de las últimas décadas del siglo XX. ${ }^{44}$

Este proceso, aquí apenas esbozado, permite llamar la atención sobre un problema teórico crucial, en relación al cual la economía parece brindar un terreno de reflexión particularmente fértil. Me refiero a los "efectos performativos" de la ciencia económica sobre la vida social, una hipótesis que se ha generalizado en la literatura reciente a partir de un texto de Michel Callon $^{45}$ y que, como hace poco han mencionado MacKenzie y Millo, ${ }^{46}$ en un trabajo que se refiere al campo de lo que los especialistas denominan "micro-economía", espera aún demostraciones empíricas plenamente convincentes. Aquí he querido sugerir que la "macro-economía" parece ser un

43 Sobre la noción de "memory bank", en una antropología del dinero y la moneda en la sociedad contemporánea, ver Harth, K.: Money in an Unequal World, Texere, New York, 2001.

44 Esto pone en evidencia la utilidad que la reconstrucción del largo y lento proceso de cultivación económica puede tener para la comprensión de los comportamientos individuales y colectivos en los momentos de crisis hiperinflacionaria, que permite avanzar respecto de las descripciones ya disponibles (como las propuestas para el caso argentino por Spitta 1988 y por Sigal \& Kessler 1997). Ciertamente las crisis son privilegiadas para el ejercicio de la pedagogía de la economía monetaria, pero sólo a condición de que puedan ser movilizadas disposiciones ya incorporadas, incluso también en periodos de relativa estabilidad y bienestar.

45 Véase la obra de Michel Callon.

46 Mackenzie, D.; Millo, Y.: "Negotianting a Market, Performing Theory: The Historical Sociology of a Financial Derivatives Exchange", American Journal of Sociology 109(1), 2003, págs. 108-110. 
terreno particularmente propicio para ensayar una demostración semejante, pues sitúa claramente el problema en el dominio de la sociología general de la cultura. Mas, específicamente, he querido sugerir que el punto de partida de tal demostración exige refinar el postulado de Callon, mostrando que si hay algo como la performatividad su agente no es la "ciencia económica" (una inexistente, abstracta y homogénea economics, con agency), sino más bien un efecto de las relaciones de interdependencia y de competencia entre profesionales de la economía que actúan al mismo tiempo en el plano de las políticas, de la academia y del mercado. ${ }^{47}$

El hecho de que esas relaciones y sus efectos estén situados en el tiempo hace que la sociología de las culturas económicas deba ser necesariamente histórica. Y el hecho de que los fenómenos tratados (incluso en lo que se refiere a su difusión o contagio) tengan como referentes espacios nacionales con fronteras obliga a que esa sociología sea también comparativa (es siempre el cuerpo de la nación el que, antes que nada, sufre el síntoma de la crisis). ${ }^{48}$

En este último sentido vale la pena notar también que a pesar de sus demandas de universalidad (sistematizadas en el lenguaje abstracto de las ecuaciones y de los números), los saberes económicos son deudores de tradiciones intelectuales nacionales, y su transformación en políticas (algo esencial para su eficacia preformativa) depende de condiciones de legitimación y de implementación que son internacionales pero también nacionales. ${ }^{49}$

Por fin, habrá que considerar que los dispositivos inventados por los economistas (como las propias monedas) son objeto de elaboraciones sociales, i.e. revestidos de significados y colocados en contextos que no son

47 La noción de "campo económico", propuesta por Pierre Bourdieu en Bourdieu, Pierre: "Le champ économique", Actes de la recherche en sciences sociales 119, 1997, págs. 48-66, parece especialmente adecuada para avanzar en una dirección semejante.

48 Los "países periféricos" no parecen tener ningún privilegio. Ver, por ejemplo, la asociación entre crisis nacional y terapia monetaria descrita, para los casos contemporáneos de Francia y de Gran Bretaña, respectivamente en Lebaron, F.: La croyence économique. Les économistes entre science et politique, Seuil, Paris, 2000, págs. 176-181 y Dixon, K.: Les évangélistes du marché, Raison d'Agir, Paris, 1998, págs. 47-60.

49 Sobre la dimensión de las tradiciones nacionales en la historia social de la economía, ver por ejemplo, Fourcade-Gourrinchas, M.: "Politics, Institutional Structures and the Rise of Economics: A Comparative Study", Theory and Society 30, 2001. Para un análisis de la producción de saberes sobre la sociedad que considera al mismo tiempo las condiciones nacionales e internacionales de su legitimación y de su implementación en una perspectiva comparativa, ver De L'Estoile, B.; Neiburg, F., y Sigaud, L. (org.): Empires, Nations and Natives. Anthropology and state-making, Duke University Press, Durham, 2005. 
siempre aquellos imaginados por los economistas. ${ }^{50}$ Pero dejemos para otra ocasión este registro del argumento, que exige examinar en profundidad los sentidos sociales vinculados a, por ejemplo, contratos, tablitas de desagio, indexadores, bonos y otras cuasi-monedas. Lo dicho hasta aquí me parece suficiente para mostrar el interés que el estudio del desequilibrio monetario tiene para una indagación sistemática sobre las culturas económicas. Sabemos que los economistas se ocupan de juzgar las causas de los éxitos y los fracasos de los planes económicos desde la perspectiva de su "consistencia interna" y que, buscando resolver el mismo misterio, los cientistas políticos acostumbran especular sobre los mecanismos de "creación de consensos" (entre partidos y sectores sociales) que dan sustento a los programas de estabilización. A las "otras" ciencias sociales (la antropología, la sociología y la historia) no les caben interrogaciones semejantes. Más bien, su objetivo debe ser (como ha sido aquí) describir la construcción social de las teorías económicas, los complejos mecanismos que les dan legitimidad y las difunden más allá del estrecho círculo de los especialistas, comprender los procesos a través de los cuales éstas se funden con otras formas de conceptuar las relaciones entre las personas y la vida en sociedad.

50 Los trabajos de Viviana Zelizer son especialmente agudos en ese sentido. 